\title{
THERMOGRAPHIC ANALYSIS OF ACOUSTIC DISTOURBANCE EFFECTS ON LAMINAR SEPARATION BUBBLE
}

\author{
R. Ricci ${ }^{\circ}$, F. Angeletti *, S. Montelpare *, A. Secchiaroli *
}

* Dipartimento di Energetica - Università Politecnica delle Marche.

- PRICOS - Università di Chieti-Pescara.

\section{Abstract}

This research is aimed to evaluate the possibility to destabilize the boundary layer in order to reduce the Laminar Bubble phenomenon; this is carried out by means of acoustic or mechanical perturbations of the flow field. The analyses are performed in a low speed wind tunnel for an Eppler 205 airfoil typically subjected to the laminar separation bubble phenomenon at low Reynolds. The effects of the acoustic perturbations on the flow pattern are revealed by means of an infrared camera and the heated thin foil technique; instead, at the present work stage, the results of the mechanical perturbations are observed by using the pressure distribution analysis.

The experimental results show, as expected, a frequency and amplitude influence on the bubble reduction. These effects are not constant varying the angle of attack for the tested airfoil neither modifying the chord based Reynolds number.

\section{Introduction}

The laminar bubble (L.B.) phenomenon (Fig. 1) is a boundary layer local separation that occurs on aerodynamic bodies operating at low Reynolds numbers; more exactly this is present when an adverse pressure gradient decelerate the velocity in the laminar boundary layer up to an inversion near the wall and it causes a laminar separation. In the event that the separated shear layer become a complete transition to a turbulent condition, a flow reattachment on the body surface may occur and the laminar bubble is formed. The bubble corresponds to the region of recirculating flow entrapped between the laminar separation point and the turbulent reattachment point.

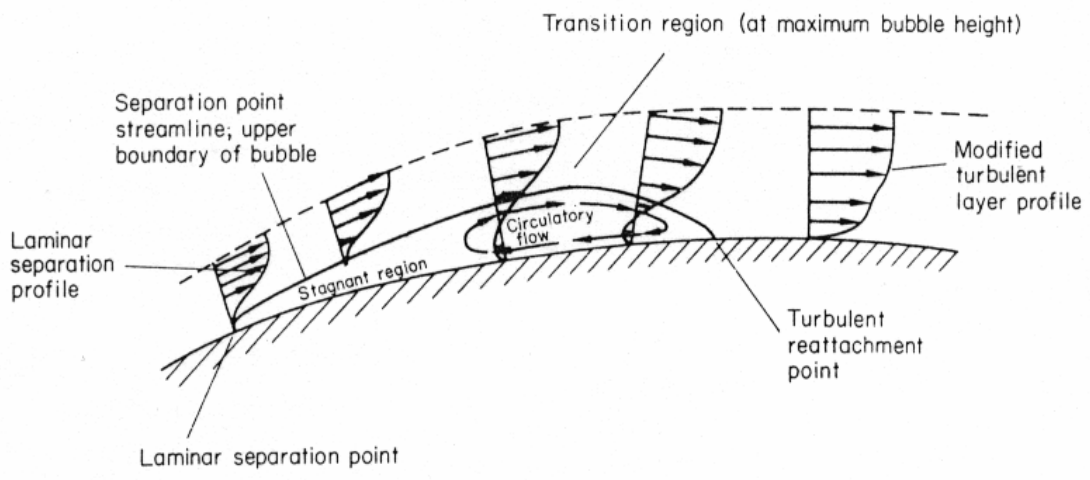

Fig. 1 Laminar Bubble Longitudinal Section 
The bubble is generally a 3-dimensional phenomenon that extends longitudinally to the flow and perpendicularly to the body surface with a finite transversal dimension. In our research the experiments are conducted on a vertical wing section that covers all the test section height; so the analysis is 2-dimensional and also the bubble shows a 2-dimensional behaviour with a constant longitudinal extension along the span.

The main problems associated with a L.B. presence are an aerodynamic drag increase with a possible lift decrease and a pressure pulsation that may induce mechanical vibrations on the structure. It comes that a bubble reduction or elimination allows a better aerodynamic body behaviour with a substantial gain. This phenomenon may occur in many fields of application: as example Unmanned Air Vehicles (UAV), wind turbine blades, sail plane wings, car body details and so on.

Actually there are different methods to control the boundary layer developing on an airfoil surface, and consequently the laminar bubble; they are subdivided in active and passive methods. The former are related to suction or blowing techniques that avoid fluid particle separation (suction) or renew exhausted particles with new and more energetic ones (blowing); these techniques are difficult to realize and involve complicated and heavy systems to be installed inside the wings. The latter are more simple and involve the use of strips attached on the body surface (turbulators) that physically induce, at a fixed point, boundary layer transition to the turbulence; the disadvantage of this method is due to an indistinct drag increase for all the work angle with no selectivity.

This research work aims to implement a boundary layer control technique that may be used only when it is necessary and that not creates disturbances when not activated. The first step is the study of acoustic disturbances supplied to the main flow at different frequencies and amplitudes; the second step is the study of an onboard system that induces pressure pulsations directly inside the boundary layer developing on the wing section.

The theoretical background for these techniques are the linear stability theory and the stability maps.

\subsection{The Theoretical Background}

The transition from laminar to turbulent motion is a complex phenomenon actually subjected to studies by the scientific community [1-4]. Experimentally was observed that there is, on the body surface, a distinct zone, defined as 'indifference point', where periodic velocity perturbation supplied to the boundary layer arise: these are the Tollmien-Schilchting waves (TS Waves). In this zone a disturbance in the free stream, may be amplified and may originate turbulent spots: the number of these spots increases until they coalesce and generate the turbulent flow.

One of the most used theory regarding the study of boundary layer transition is due to Orr and Sommerfeld; it is called 'linear stability theory' or 'small perturbance theory'. In this approach a perturbed motion field is superimposed to the main flow. The perturbed field is characterized by oscillatory velocity component having small amplitude. The superimposed motion is introduced in the Stokes-Navier equations, reducing the system to an eigenvalue/eigenfunction problem represented by a single IV order ordinary differential equation called Orr-Sommerfeld Equation (O.S.E. eq.1)

$$
(u-c)\left(\varphi^{\prime \prime}-\alpha^{2} \varphi\right)-u^{\prime \prime} \varphi=-\frac{i \nu}{\alpha}\left(\varphi^{\prime \prime \prime}-2 \alpha^{2} \varphi^{\prime \prime}+\alpha^{4} \varphi\right)
$$


In order to solve the O.S.E. a velocity profile $u(y)$ is imposed inside the boundary layer. The laminar boundary layer velocity profiles are expressed by introducing the Polhausen parameter (eq. 2) related to the integral approach to the boundary layer Prandtl equations.

$$
\Lambda=\frac{\delta^{2}}{v} \frac{d U_{e}}{d x}
$$

Negative values of $\Lambda$ correspond to adverse local pressure gradients. This parameter describes the velocity profile inside the boundary layer through a fourth order polynomial law (eq. 3).

$$
\bar{u}=2 \bar{y}-2 \bar{y}^{3}+\bar{y}^{4}+\frac{\Lambda}{6}\left(\bar{y}-3 \bar{y}^{2}+3 \bar{y}^{3}-\bar{y}^{4}\right)
$$

The previous equations allows to obtain the boundary layer characteristic parameters: i.e. the displacement thickness $\delta_{1}$, the momentum thickness $\delta_{2}$ and the shape factor $\mathrm{H}_{12}$ (eqs. 4-6).

$$
\begin{array}{r}
\overline{\delta_{1}}=\int_{0}^{1}(1-\bar{u}) d \bar{y}=\frac{3}{10}-\frac{\Lambda}{120} \\
\bar{\delta}_{2}=\int_{0}^{1} \bar{u}(1-\bar{u}) d \bar{y}=\frac{1}{63}\left(\frac{37}{5}-\frac{\Lambda}{15}-\frac{\Lambda^{2}}{144}\right) \\
H_{12}=\frac{\bar{\delta}_{1}}{\bar{\delta}_{2}}
\end{array}
$$

The eigenvalues and the selected velocity profile allow to draw different stability maps [1] depending on the Polhausen parameter (Fig. 2a).

The graph axes reports adimensionalized eigenvalues which affect the stability of the T.S. waves: wave number versus $\mathbf{R e}_{\delta \mathbf{1}}$. Moving inside the curves the boundary layer results unstable so the T.S. waves are amplified. By this way the local pressure gradient effect is clearly showed: curves more opened characterized by negative values of $\Lambda$ correspond to more unstable boundary layers.

So it should exist a sound wave with particular frequency (i.e. wave number) which amplifies the T.S. Waves. Introducing this sound in the free stream, upstream the airfoil, a boundary layer transition can be forced to happen. The aim of this work is the investigation of the phenomenon by an IR technique in order to better understand the involved parameters. Before the experimental analysis a theoretical and numerical study is performed in order to evaluate if the indifference point is located upstream the separation point, for the selected airfoil, and then if the transition with selected frequencies may be produced.

The procedure to obtain the indifference point involves the Wazzan curve [1] which relates the Reynolds number evaluated at the indifference condition $\left(\mathbf{R e}_{\delta 1, \text { ind }}\right)$ with the boundary layer Shape Factor $\mathbf{H}_{12}$ (Fig. $2 b$ ). For the present work the curve is coupled with data carried out by the M. Drela's freeware X-Foil numerical software, 
frequently used for the study of aerodynamic two-dimensional airfoils. This numerical code calculates $\mathbf{R e}_{\delta 1}$ versus $\mathbf{H}_{12}$ at different angles of attack (Fig. 3) and so it is consequently possible to cross the resulting curves with the Wazzan graph. As is possible to observe, the Wazzan curve intersect the E205 curves before the separation point for all tested angles (the curves are graphed only for the coordinates upstream the laminar separation point). So, referring to the theory, there could be present frequencies able to destabilize the boundary layer before the laminar bubble occurs.
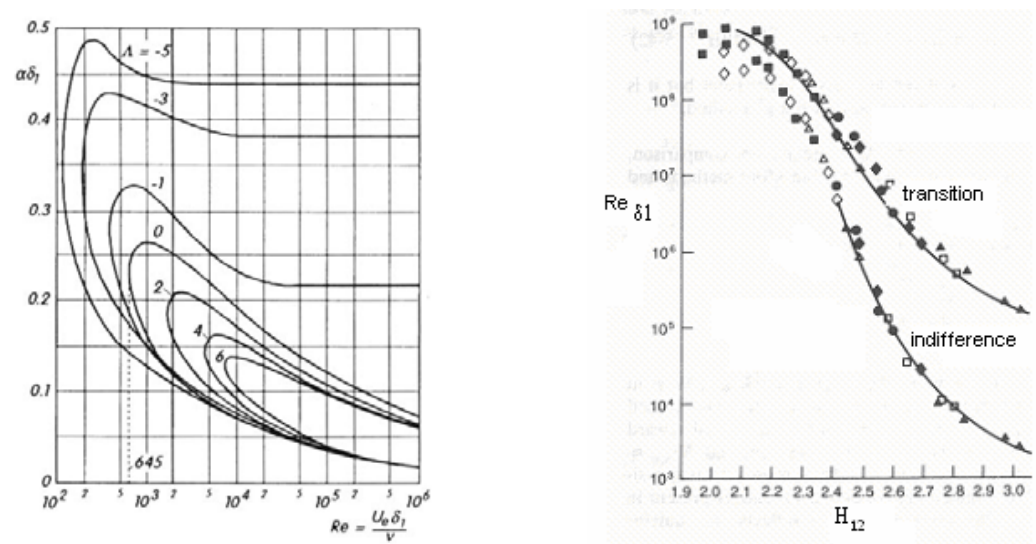

Fig. 2 (a) Stability Maps [1] - (b) Wazzan Curve [1]

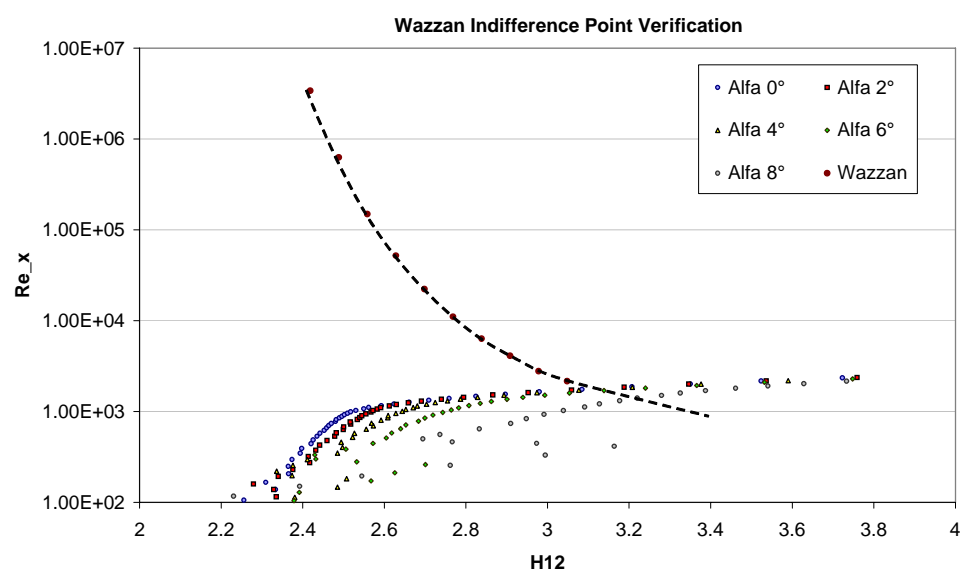

Fig. 3 Indifference point calculation for the E205 profile at various angle of attack

\section{The Experimental Apparatus}

All test are conduced in low speed wind tunnel (Fig. 4) available at the "Dipartimento di Energetica" of the University "Politecnica delle Marche"; this is an open loop circuit having the subsequent characteristics: 
- $\quad$ test section dimensions: $620(\mathrm{~W}) \times 380(\mathrm{H}) \times 1500(\mathrm{~L})[\mathrm{mm}]$

- $\quad$ inlet test section area contraction ratio: 4.65

- maximum velocity: $38\left[\mathrm{~ms}^{-1}\right]$

- mean turbulence in the inlet section: $0.3 \%$

- fan power $5.5 \mathrm{~kW}$ and revolution numbers controlled by an inverter

The sound source, a $38 \mathrm{~cm}$ diameter sub-woofer, is placed in front of the wind tunnel inlet and is connected to a $500 \mathrm{~W}$ amplifier controlled by a signal generator able to produce a pure tone.

The sound pressure level (SPL) is measured by a B\&K $1 / 4$ inch microphone connected to a B\&K spectrum analyzer. The test are conducted both in $1 / 3$ and $1 / 24$ octave.

The air flow velocity and turbulence level are measured by a DANTEC CTA single hot wire anemometer.

The thermographic apparatus is composed by: a FLIR SC3000 LongWave focal plane array IR camera and a ZnSe IR window placed on the lateral side of the test section. The IR Scanner has a thermal accuracy of $30 \mathrm{mK}$ and an array of $320 \times 240$ sensors. The high spatial resolution and thermal accuracy allows to realize the above described quantitative approach to the study of the bubble. The IR scanner is connected to a PC by its PCMCIA interface in order to allow the recordings of the images through the 'ThermaCAM Researcher' software and the subsequent postprocessing utilizing the MatLab routines.

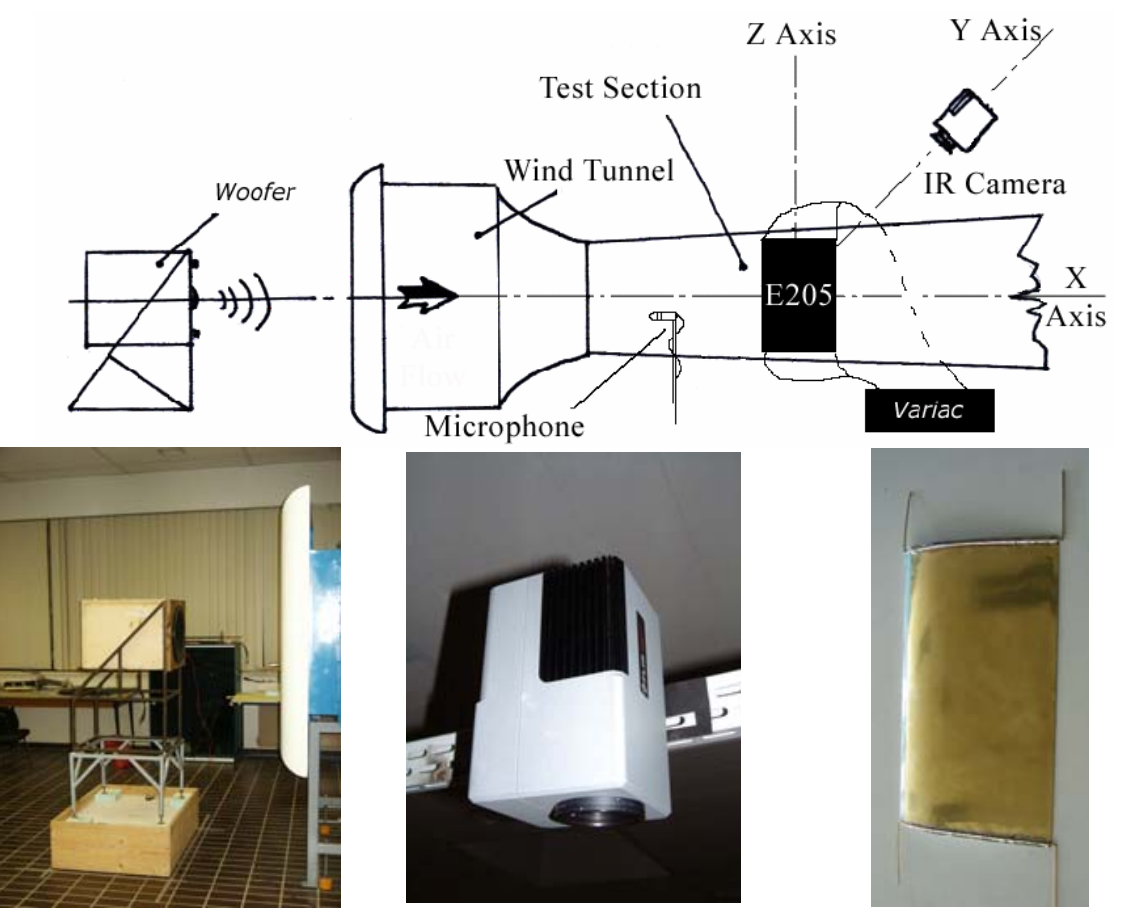

Fig. 4 Experimental Apparatus

Two different wing sections based on the same airfoil (E205) are realized in order to perform the infrared analysis and the pressure tests. The wing section used 
for the IR measurements is obtained by laminating fiber glass over an extruded polystyrene section modelled on the E205 airfoil. A thin foil (25 micron) of brass is glued over the upper surface and a constant current is supplied from both the lateral sides. This arrangement ensure both a constant and uniform heat flux by Joule effect and the adiabatic boundary condition on the lower side of the brass foil ( the glued side). The wing section is painted with dull black paint having an emissivity of 0.94 before the IR visualizations.

The wing section used for the pressure distribution analysis is realized by joining two fiber glass shells previously equipped with pressure taps. This model is equipped with a micro electro mechanical system (M.E.M.S.) placed in the first ten per cent of the airfoil chord; this piezoelectric device induces pressure pulsation directly inside the developing boundary layer when an alternating electric current is supplied. The frequency and amplitude of the oscillations are controlled by varying the supplied current.
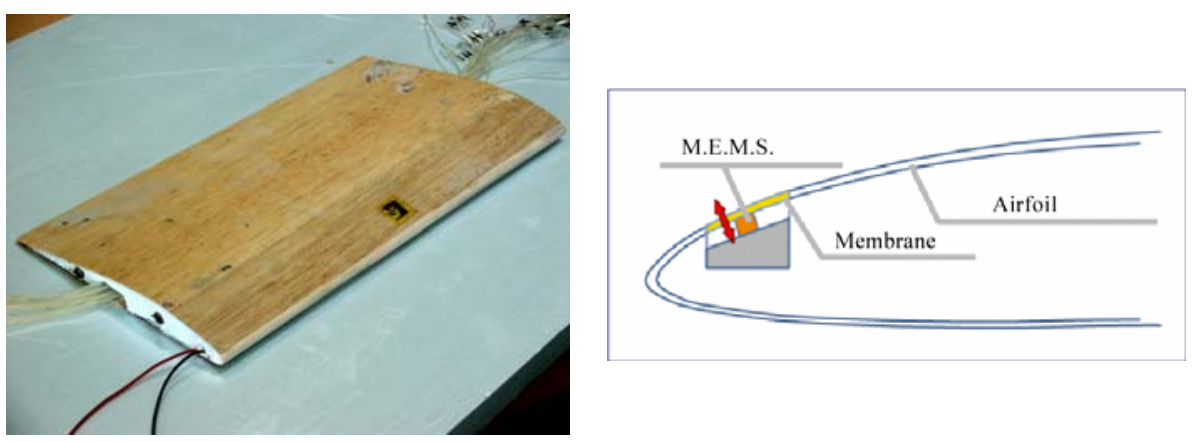

Fig. 5

The Wing Section equipped with M.E.M.S. and pressure taps

\section{Experimental Results}

\subsection{Acoustic Disturbances}

The thermographic analyses are preceded by an acoustic characterization of the sound pressure level (S.P.L.) inside the test section. In order to verify the uniformity of the sound pressure field a grid of measurements $(45 \mathrm{~cm} \times 35 \mathrm{~cm}$, with a constant step of $5 \mathrm{~cm}$ ) is performed upstream the wing section. The figure 6 reports a colour map of the maximum sound pressure levels for the scanned grid (left image) at $150[\mathrm{~Hz}]$ and the sound pressure levels at the same woofer frequency for the vertical central line (right image).

The current and voltage supplied to the woofer by the amplifier are collected in order to overcome the woofer impedance variation by varying the pure tone frequency selected and to obtain a constant S.P.L. inside the test section.

The results show (Fig. 6a) an appreciable uniformity of the maximum sound pressure level for the scanned section at 150 [Hz], this uniformity is present up to 500 $[\mathrm{Hz}]$; for frequencies higher than this value the sound pressure field becomes not uniform. A detailed analysis of the S.P.L. at frequencies of $1 / 3$ octave band (Fig. 6b) shows that the frequency supplied by the woofer is reported inside the test section without shifts and also that the S.P.L. corresponding to the exciting frequency is higher $(>20 \mathrm{db})$ than the other ones. 


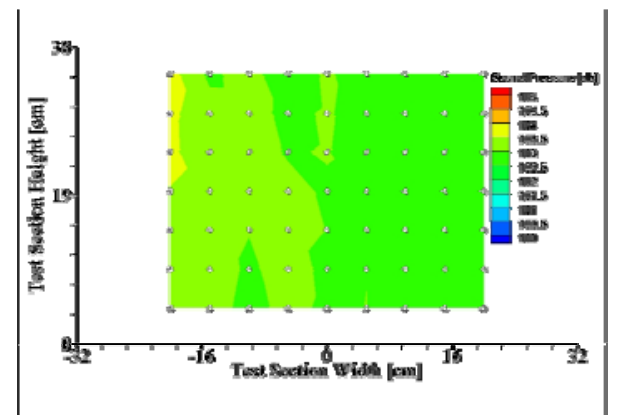

(a)

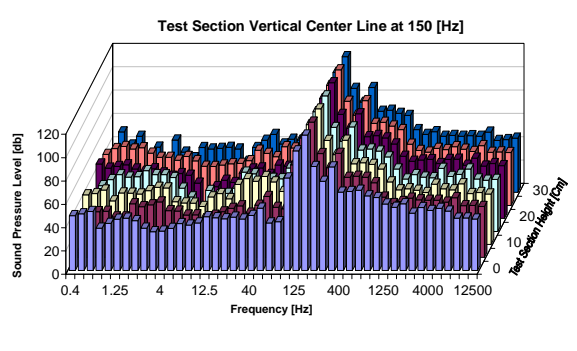

(b)

Fig. 6 Sound Pressure Field Inside the test section at $150[\mathrm{~Hz}]$

Once verified the S.P.L. field uniformity the thermographic analyses are carried out. For each angle of attack and Reynolds number the thermal images are acquired for "No-Heated-Foil condition", 50 images, and for "Heated Foil Condition", 50 images (Fig. 7).

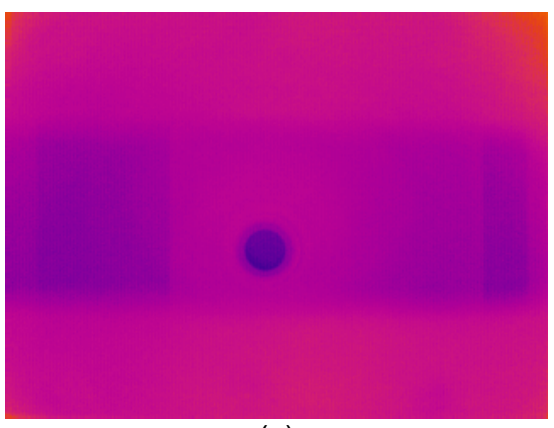

(a)

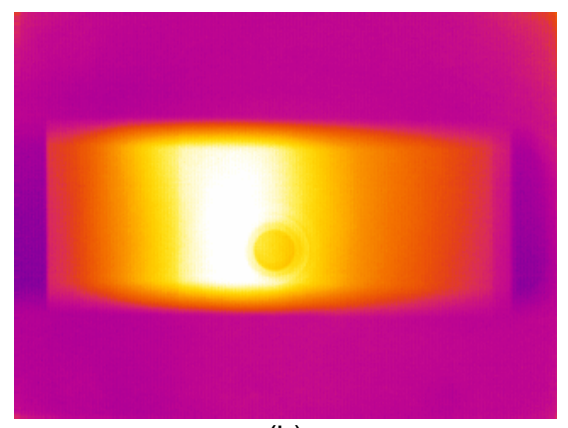

(b)

Fig. 7 Thermal Background Image (a) and Thermal Test Image (b)

A custom Matlab ${ }^{\odot}$ procedure is developed to analyze the thermograms according to the subsequent procedure:

- $\quad$ Averaging of the fifty images;

- Subtraction between the background and the test images (to reduce "narcissus effect");

- Image filtering based on the IR camera thermal accuracy level;

- Spatial average for the temperature information in the span direction among pixels ranging from the airfoil center section to \pm 25 pixel;

- Evaluation of the convective heat transfer $\mathbf{h}$ coefficient along the airfoil chord on the basis of energy conservation approach (Fig. 8) (equation 7);

- Computation of the inviscid velocity distribution $\mathbf{U}_{e}$ on the E205 airfoil upper surface, for the same wind tunnel tested conditions, by means of X-Foil numerical code;

- Calculation of the local Stanton number based on the $\mathbf{U}_{\mathbf{e}}$ 
- $\quad$ Analysis of the first and second derivative for the St distribution to identify the laminar separation point (L.S.P), the transition point (T.P) and the turbulent reattachment point (T.R.P.)

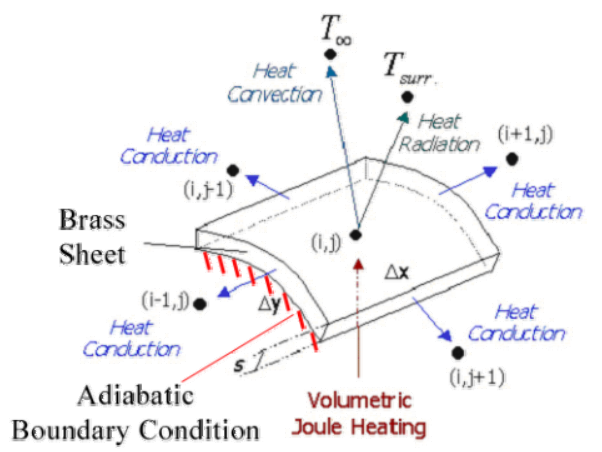

Fig. 8 Energy Conservation Approach

$$
\begin{aligned}
& \frac{T(i+1, j)-T(i, j)}{\frac{\Delta x}{k \cdot s \cdot \Delta y}}+\frac{T(i-1, j)-T(i, j)}{\frac{\Delta x}{k \cdot s \cdot \Delta y}}+\frac{T(i, j+1)-T(i, j)}{\frac{\Delta y}{k \cdot s \cdot \Delta x}}+ \\
& +\frac{T(i, j-1)-T(i, j)}{\frac{\Delta y}{k \cdot s \cdot \Delta x}}+h \cdot \Delta x \cdot \Delta y \cdot\left(T_{\infty}-T(i, j)\right)+ \\
& +\sigma \cdot \frac{T_{\text {surr. }}^{4}-T^{4}(i, j)}{\frac{1-\varepsilon}{\varepsilon \cdot \Delta x \cdot \Delta y}+\frac{1}{F_{12} \cdot \Delta x \cdot \Delta y}+\frac{1-\varepsilon_{\text {surr. }}}{\varepsilon_{\text {surr. }} \cdot A_{\text {surr. }}}}+G \cdot \Delta x \cdot \Delta y \cdot s=0
\end{aligned}
$$

The analysis of the Stanton and its derivatives distributions (Fig. 9) is carried out on the basis of literature information [5] and fluid dynamic considerations [6-7]. The bubble presence, with a boundary condition of fixed heat flow and a forced convective heat exchange, generates a temperature distribution that shows a local increase in coincidence with the laminar bubble; this because the re-circulating flow inside the local boundary layer separation has a low convective heat transfer coefficient $\mathbf{h}$ and so there is not a good thermal exchange. The transition point, corresponding to the maximum bubble height, will be appreciate as the minimum Stanton number. The laminar separation point will be underlined by a substantial modification in the Stanton developing trend before the transition point (mathematically a point of inflection). The turbulent reattachment point corresponds to a jet impingement on the airfoil surface with an abrupt heat transfer increase and consequently with an exchange in the Stanton trend after the transition. 
http://dx.doi.org/10.21611/qirt.2006.074

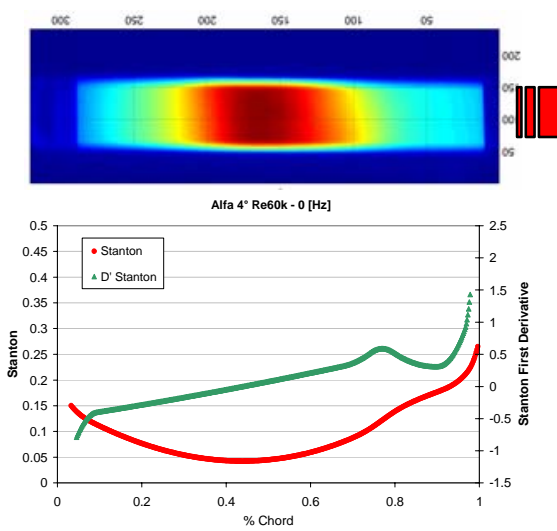

(a)

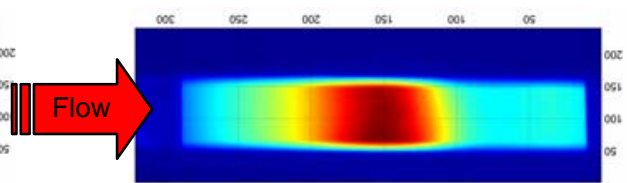

Alfa $4^{\circ}$ Re60k - $100[\mathrm{~Hz}]$

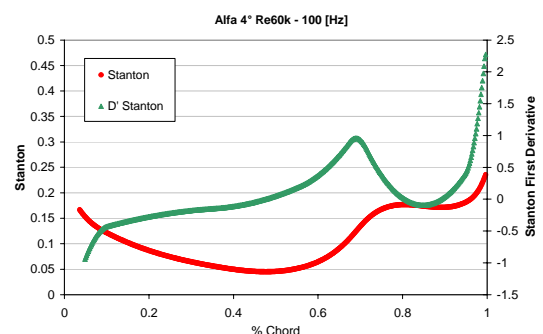

(b)

Fig. 9 Stanton and Stanton First Derivative distribution with no sound(a) and with a sinusoidal pure tone sound of $100[\mathrm{~Hz}]$

The test results show an appreciable effect of the sound disturbances on the boundary layer development; there is not a unique frequency that interacts with the laminar bubble phenomenon but there is a range of frequencies that shows a good effect on the laminar bubble extension with a visible reduction. By varying the airfoil angle of attack and the Reynolds number, the frequency that induces the higher reduction modifies; this results is justified by remembering that these two parameters change the boundary layer height, the pressure distribution and the boundary layer development. Tabulating the positions of the L.S.P., T.P. and T.R.P. as function of chord and alfa it is possible to build a graph as reported in figure 10, where the bubble dimension is parametrized with the sinusoidal pure tone woofer frequency.

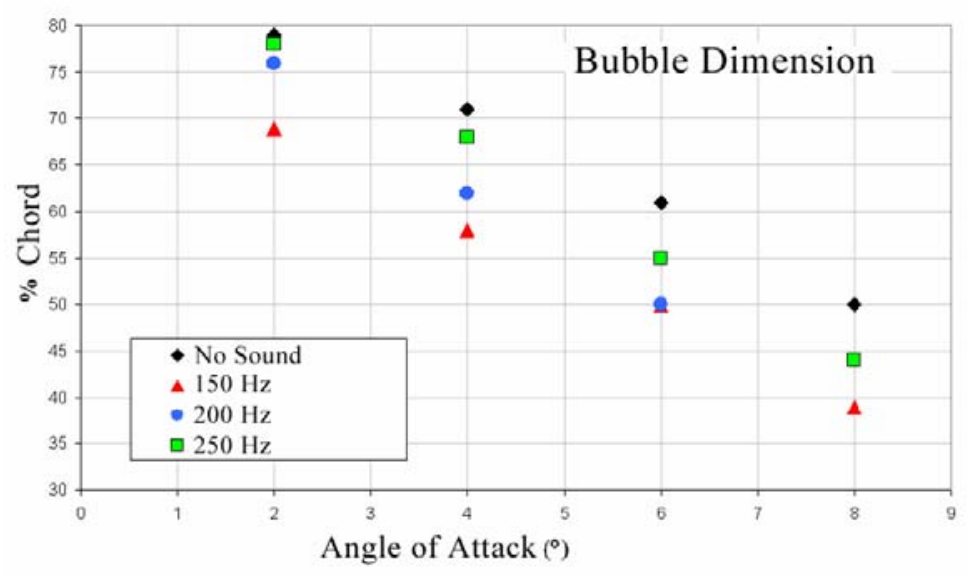

Fig. 10 Modification of the Laminar Bubble Dimension by varying the Woofer frequency $(R e=60 \mathrm{k})$ 


\subsection{Mechanical Disturbances Preliminary Results}

Preliminary results are also reported for the study of the boundary layer destabilization by vibrating M.E.M.S. inserted under the airfoil surface. The tests are carried out at the same frequencies that show a laminar bubble reduction for the acoustic destabilization (i.e. $100 \div 250$ [Hz]), at the same airfoil angle of attack range and at Reynolds 60k.

The results show that the mechanical system do not appear to be useful for all the angles where the bubble is present. The figure 11 reports the analysis at alfa $0^{\circ}$ for different frequencies: there are not pressure distribution variations above the instrument uncertainty for any of the tested frequencies.

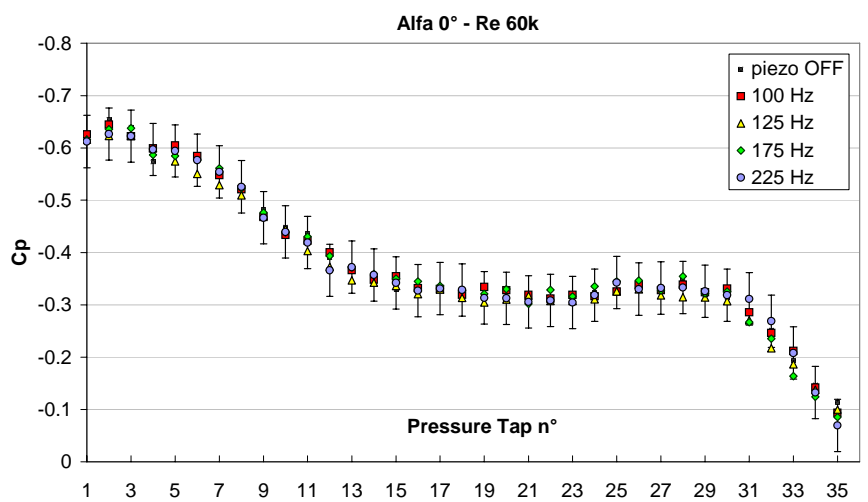

Fig. 11 Pressure distribution analysis for alfa $0^{\circ}$ and Reynolds $60 \mathrm{k}$

The results for alfa $4^{\circ}$ show contrary an effect on the bubble behaviour; in particular the higher frequencies modify the pressure distribution slope before the laminar separation and before the turbulent reattachment.

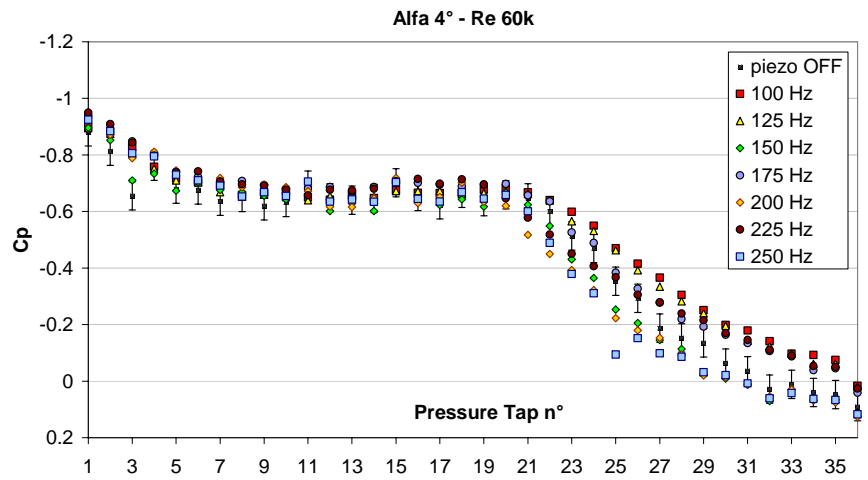

Fig. 12 Pressure distribution analysis for alfa $4^{\circ}$ and Reynolds $60 \mathrm{~K}$ 


\section{REFERENCES}

[1] F.M. White, "Viscous Fluid Flows", Int. Edition, ISBN 0-07-100995-7

[2] M. Nishioka, M. Asai, S. Yoshida, "Control of flow separation by acoustic excitation", AIAA Journal, vol.28, n¹1, Nov.1990

[3] C. Haggmark, "Investigation of disturbance developing in a laminar separation bubble flow", Technical reports from Royal Institute of Technology, Department of Mechanics S-100 44 Stockholm, Sweden, 2000

[4] W.S. Saric, H.L. Reed, E.J. Kerscen, "Boundary layer Receptivity to freestream disturbances", Annu. Rev.Fluid Mech. 34, pp 291-319, 2002

[5] T. Astarita, G. Cardone, G.M. Carlomagno, C. Meola, "A survey on infrared thermography for convective heat transfer measurements", Optics \& Laser Technology 32, pp 593-610

[6] G. Cesini, R. Ricci, S. Montelpare, E. Silvi, "A thermographic method to evaluate laminar bubble phenomena on airfoil operating at low Reynolds number", QIRT 2002, 2002

[7] S. Montelpare, R. Ricci, "A thermographic method to evaluate the local boundary layer separation phenomena on aerodynamic bodies operating at low Reynolds number", International Journal of Thermal Sciences 43 (2004) 315329, July 2003 


\begin{tabular}{|c|c|c|c|c|c|}
\hline \multicolumn{6}{|c|}{ Nomenclature } \\
\hline$A$ & surface & $\mathrm{m}^{2}$ & $\delta_{1}$ & displacement thickness & $\mathrm{m}$ \\
\hline$c$ & $\begin{array}{l}\text { phase velocity of small } \\
\text { disturbance }\end{array}$ & $\mathrm{m} \mathrm{s}^{-1}$ & $\delta_{2}$ & momentum thickness & $\mathrm{m}$ \\
\hline C & airfoil chord length & $\mathrm{m}$ & $\varepsilon$ & emissivity & \\
\hline$f$ & frequency & $\mathrm{Hz}$ & $\varphi$ & $\begin{array}{l}\text { disturbance amplitude } \\
\text { function }\end{array}$ & \\
\hline$F_{12}$ & $\begin{array}{l}\text { view factor for thermal } \\
\text { radiation }\end{array}$ & & $\lambda$ & wavelength & $\mu \mathrm{m}$ \\
\hline$G$ & $\begin{array}{l}\text { internal heat } \\
\text { generation }\end{array}$ & W & $\Lambda$ & Polhausen parameter & \\
\hline$h$ & $\begin{array}{l}\text { convective heat } \\
\text { transfer coefficient }\end{array}$ & $W m^{-2} K^{-1}$ & $v$ & kinematic viscosity & $m^{2} s^{-1}$ \\
\hline$H_{12}$ & $\begin{array}{l}\text { boundary layer shape } \\
\text { factor }\end{array}$ & & $\sigma$ & $\begin{array}{l}\text { Stephan-Boltzmann } \\
\text { constant }\end{array}$ & \\
\hline$i$ & imaginary unit & & & & \\
\hline$k$ & thermal conductivity & $\mathrm{W} \mathrm{m}^{-1} \mathrm{~K}^{-1}$ & \multirow{2}{*}{\multicolumn{2}{|c|}{ Subscripts }} & \\
\hline $\operatorname{Re}$ & Reynolds number & & & & \\
\hline$s$ & $\begin{array}{l}\text { thickness of aluminium } \\
\text { sheet }\end{array}$ & $\mu \mathrm{m}$ & surr. & surrounding surfaces & \\
\hline$S P L$ & sound pressure level & $\mathrm{dB}$ & $\infty$ & $\begin{array}{l}\text { condition of the free } \\
\text { stream }\end{array}$ & \\
\hline$u$ & $\begin{array}{l}\text { velocity inside } \\
\text { boundary layer }\end{array}$ & $\mathrm{m} \mathrm{s}^{-1}$ & ind. & $\begin{array}{l}\text { relative to indifference } \\
\text { point }\end{array}$ & \\
\hline$U_{e}$ & $\begin{array}{l}\text { velocity at the edge of } \\
\text { boundary layer }\end{array}$ & $\mathrm{m} \mathrm{s}^{-1}$ & $i j$ & element of the finite & \\
\hline$x, y$ & $\begin{array}{l}\text { coordinates relative to } \\
\text { airfoil surface } \\
\text { coordinates relative to }\end{array}$ & $\mathrm{m}$ & , J & difference scheme & \\
\hline$X, Y$ & $\begin{array}{l}\text { wind tunnel test } \\
\text { section }\end{array}$ & $\mathrm{m}$ & & & \\
\hline & & & \multicolumn{2}{|c|}{ Superscript } & \\
\hline \multicolumn{2}{|c|}{ Greek Symbols } & & - & $\begin{array}{l}\text { Adimensionalized by } U_{e} \\
\text { or } \delta\end{array}$ & \\
\hline$\alpha$ & wave number & & $"$ & second derivative & \\
\hline$\delta$ & $\begin{array}{l}\text { boundary layer } \\
\text { thickness }\end{array}$ & $\mathrm{m}$ & ,', & fourth derivative & \\
\hline
\end{tabular}

$$
\begin{aligned}
& \alpha=\frac{2 \pi}{\lambda} \quad \text { Wave number of small disturbance } \\
& \operatorname{Re}_{\delta_{1}}=\frac{U_{e} \delta_{1}}{v} \quad \begin{array}{l}
\text { Reynolds number based on displacement thickness and edge } \\
\text { velocity }
\end{array} \\
& \operatorname{Re}_{x, U_{e}}=\frac{U_{e} x}{v} \quad \text { Reynolds number based on local abscissa and edge velocity } \\
& S t_{x, U_{e}}=\frac{N u_{x}}{\operatorname{Re}_{x, U_{e}} \cdot \operatorname{Pr}} \quad \begin{array}{l}
\text { Stanton number based on the inviscid boundary layer outer } \\
\text { velocity }
\end{array}
\end{aligned}
$$

